\title{
Crystallization Diagram for Antisolvent Crystallization of Lactose: Using Design of Experiments To Investigate Continuous Mixing- Induced Supersaturation
}

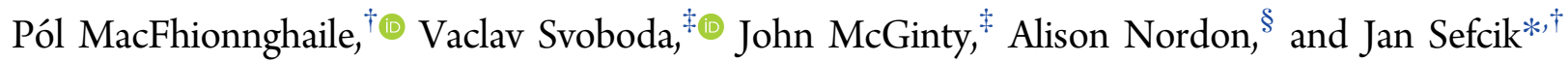 \\ ${ }^{\dagger}$ EPSRC Centre for Innovative Manufacturing in Continuous Manufacturing and Crystallization, Department of Chemical and \\ Process Engineering, University of Strathclyde, 75 Montrose Street, Glasgow G1 1XJ, United Kingdom \\ ${ }^{\ddagger}$ EPSRC Doctoral Training Centre in Continuous Manufacturing and Crystallization, Department of Chemical and Process \\ Engineering, University of Strathclyde, 75 Montrose Street, Glasgow G1 1XJ, United Kingdom \\ ${ }^{\S}$ EPSRC Centre for Innovative Manufacturing in Continuous Manufacturing and Crystallization, Department of Pure and Applied \\ Chemistry, University of Strathclyde, 295 Cathedral Street, Glasgow G1 1XL, United Kingdom
}

\section{Supporting Information}

ABSTRACT: This study investigates the effects of key process parameters of continuous mixing-induced supersaturation on the antisolvent crystallization of lactose using D-optimal Design of Experiments (DoE). Aqueous solutions of lactose were mixed isothermally with antisolvents using a concentric capillary mixer. Process parameters investigated were the choice of antisolvent (acetone or isopropanol), concentration of lactose solution, total mass flow rate, and the ratio of mass flow rates of lactose solution and antisolvent. Using a D-optimal DoE a statistically significant sample set was chosen to explore and quantify the effects of these parameters. The responses measured were the solid state of the lactose crystallized, induction time, solid yield and particle size. Mixtures of $\alpha$-lactose

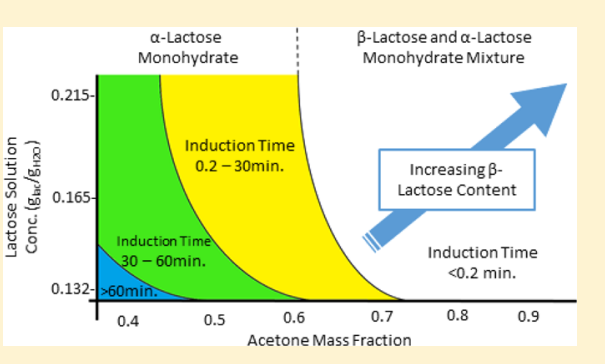
monohydrate and $\beta$-lactose were crystallized under most conditions with $\beta$-lactose content increasing with increasing amount of antisolvent. Pure $\alpha$-lactose monohydrate was crystallized using acetone as the antisolvent, with mass flow ratios near 1:1, and near saturated solutions of lactose. A higher resolution DoE was adopted for acetone and was processed using multivariate methods to obtain a crystallization diagram of lactose. The model was used to create an optimized process to produce $\alpha$-lactose monohydrate and predicted results agreed well with those obtained experimentally, validating the model. The solid state of lactose, induction time, and solid yield were accurately predicted.

\section{INTRODUCTION}

Lactose is found in the milk of most mammals and is a commercial commodity in the food and pharmaceutical industries. ${ }^{1}$ Due to its variety of application as a sweetener and excipient, lactose has been of great industrial and academic interest. ${ }^{2}$ Its synthesis and chemistry as a naturally occurring sugar has been extensively studied, ${ }^{3,4}$ as well as its interaction with proteins, ${ }^{5}$ crystallization and purification, ${ }^{6}$ physical properties, and role in secondary processing. ${ }^{7-9}$

Lactose is a disaccharide consisting of galactose and glucose, linked by a $\beta-1 \rightarrow 4$ glycosidic linkage. In aqueous solution the hydroxyl group on the $\mathrm{Cl}$ carbon of the glucose interchanges between the $\alpha$ or $\beta$ anomer (Figure 1). ${ }^{10,11}$ This phenomenon known as mutarotation occurs with ease so that either the $\alpha$ or $\beta$ anomer of lactose can precipitate from solution, posing a unique challenge in lactose crystallization. ${ }^{12}$ In an aqueous solution at neutral $\mathrm{pH}$ lactose will equilibrate at $37 \% \alpha$-lactose and $63 \% \beta$-lactose. ${ }^{13}$ This equilibrium has been reported to be achieved within $3.5-6 \mathrm{~h}$ at room temperature. ${ }^{11,14,15}$ Previous studies have shown the effects in reducing the rate of mutarotation by using dimethyl sulfoxide as a solvent hindering transformation to $\beta$-lactose, and allowing specific crystal growth of $\alpha$-lactose to dominate. ${ }^{16}$

$\alpha$-Lactose and $\beta$-lactose exist in several solid forms (Figure $1)$. Lactose is known to crystallize as $\beta$-lactose anhydrous prepared from near boiling aqueous lactose solutions ${ }^{17}$ or heated pyridine solutions. ${ }^{18-20}$ The most common commercial solid state of $\alpha$-lactose is the hydrate form, $\alpha$-lactose monohydrate obtained from cooling crystallization in $\mathrm{pH}$ neutral aqueous solutions. Other solid states include stable and unstable forms of $\alpha$-lactose anhydrous can be prepared by heating solid samples of $\alpha$-lactose monohydrate. ${ }^{21}$ A $1: 1 \alpha / \beta$ co-crystal has also been reported. ${ }^{22-24}$ Amorphous lactose has been prepared using spray drying, and depending on the conditions during preparation it can consist of varying degrees of both anomers, ranging from $>95 \% \alpha$-lactose to $<40 \% \alpha$ lactose. $^{24,25}$

Seeded cooling crystallization is commonly used as a method to crystallize $\alpha$-lactose monohydrate due to its stability at

Received: January 26, 2017

Revised: $\quad$ March 21, 2017

Published: March 28, 2017 


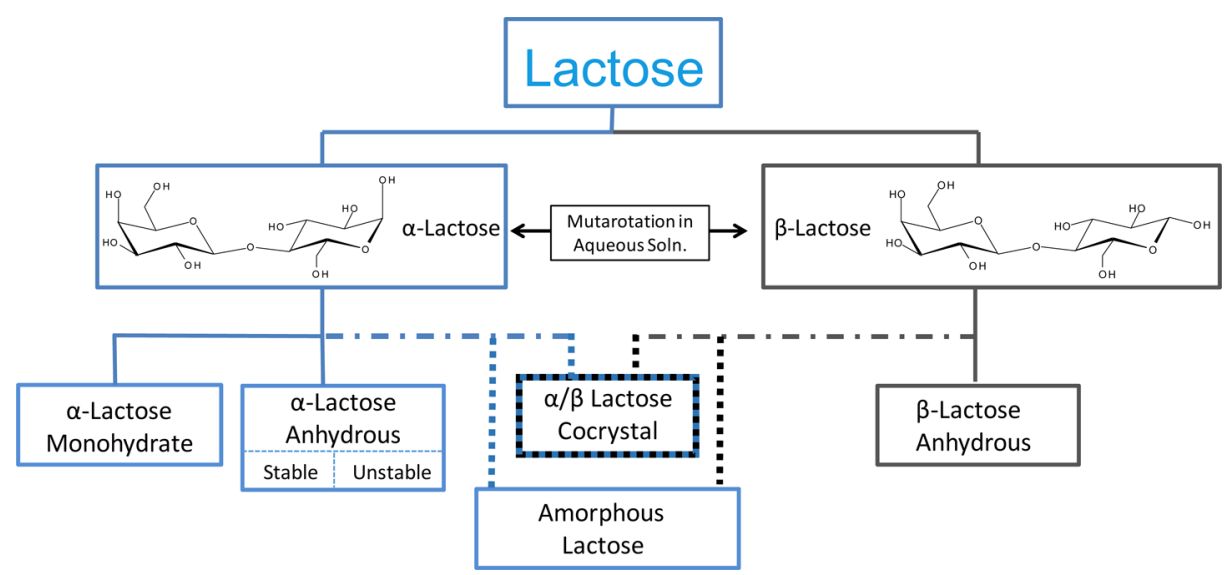

Figure 1. Overview of lactose solid states.

ambient temperatures and temperature dependent solubility profile in water. Seeding to crystallize $\alpha$-lactose monohydrate is important because nucleation during the cooling crystallization of lactose from water has induction times ranging from days to weeks. ${ }^{26-28}$ Even with seeded cooling crystallization there are well-known issues with fines and varied crystal morphology. Though $\alpha$-lactose monohydrate is most commonly known to crystallize in a unique tomahawk crystal habit it has many alternative morphologies which have shown to affect downstream processing ${ }^{29,30}$ and the final product properties. ${ }^{9,12}$ By changing the morphology of $\alpha$-lactose monohydrate improvements have made its application as an aerosol excipient viable ${ }^{31}$ and improved the texture of ice cream. ${ }^{32,33}$

Antisolvent crystallization has been suggested to tackle some of these issues by providing additional means to control nucleation control, growth rates, and resulting morphologies. ${ }^{34}$ For the antisolvent crystallization of $\alpha$-lactose monohydrate it is necessary to use water as the solvent. Larhrib et al. (2003) focused on the crystal growth, solid state, morphology, and aggregation of lactose crystallized from aqueous solutions using different amounts of acetone. ${ }^{35}$ Leviton et al. (1949) added methanol to create a final $65-75 \%$ methanol/water solution at $15{ }^{\circ} \mathrm{C}$ to extract lactose from protein whey. ${ }^{36}$ Crisp et al. (2011) observed that polymorphic selection is possible when mixing different compositions of methanol and a solution of lactose in water. ${ }^{6}$ By changing the proportion of methanol in the final mixture, it was possible to crystallize $\alpha$-lactose monohydrate (50-60\% methanol), mixtures of $\alpha$-lactose monohydrate and $\beta$-lactose $(60-95 \%$ methanol), and $\beta$-lactose anhydrous ( $>95 \%$ methanol). Brito et al. (2007) measured the changes in the metastable zone width resulting from increasing the acetone mass ratio in lactose solutions of water. ${ }^{37}$ Machado et al. (2000) used a modified UNIversal QUAsiChemical (UNIQUAC)-based model to predict the solubility of lactose in solutions of water and ethanol at different temperatures. ${ }^{38}$ This model was found to compare well with experimental results. Though the work of Brito et al. (2007) and Machado (2000) investigated the solubility of lactose in different solvent/ antisolvent mixtures, the solid forms of lactose were not specified.

Continuous methods of cooling crystallization for lactose have been popular due to its ability to produce particles with consistent morphology and size. ${ }^{39,40}$ Shi et al. (1990) used water and ethanol as the solvent and antisolvent, respectively, for the continuous crystallization of lactose. ${ }^{41} \mathrm{~A}$ study conducted by Bund et al. (2007) investigated the effects of sonication, concentration, and $\mathrm{pH}$, in the extraction of lactose from buffalo whey using continuous antisolvent crystallization methods. ${ }^{42}$ Here it was found that a $90 \%$ ethanol in water solution was the optimal solvent/antisolvent composition for the recovery of lactose, though the lactose solid state recovered was not reported. Dong et al. (2010) used antisolvent crystallization coupled with continuous mixing to co-precipitate spironolactone and lactose obtaining uniform particle size fit for aerosol inhalation formulation. ${ }^{43}$ This study was conducted using a static mixer and focused on scaling up production from a 1 to $3 \mathrm{~L} / \mathrm{min}$ process. The work of Rjabova et al. (2003) showed the capability of integrating continuous methods to improve the recovery of lactose. ${ }^{44}$ Other studies have shown success in obtaining a greater crystal yield, smaller particles with a more uniform size distribution when using $>90 \%$ of antisolvent giving anomeric mixtures, ${ }^{31}$ and in some cases inducing polymorphic change ${ }^{45}$ indicating that majority of polymorphic events occur at high concentrations of antisolvent.

DoE has been previously used to optimize antisolvent ${ }^{46}$ and combined cooling/antisolvent crystallization ${ }^{47}$ under batch conditions. We have recently used DoE to achieve solid form control in batch co-crystallization and, based on this, implemented a continuous mixing-induced co-crystallization process. ${ }^{48}$ However, we are not aware of any previous work on direct application of DoE to continuous crystallization processes. A continuous approach to generating mixing-induced supersaturation using a static mixer provides well controlled steady state mixing of inlet solution streams, allowing the mixing regime to be changed by varying mass flow rates. ${ }^{48}$ In this work, we used a concentric capillary static mixer where undersaturated solutions of lactose were continuously mixed with an antisolvent. A Design of Experiment was used to obtain a statistically significant sample set to assess the effects of the key process parameters of the continuous mixing process on antisolvent crystallization of $\alpha$-lactose monohydrate: antisolvent choice (acetone or isopropanol), lactose solution concentration, mass flow rate ratio, and total mass flow rate. A crystallization diagram describing solid state outcomes, solid yield, and induction time was obtained using the key process parameters (mass flow ratio of solutions, lactose concentration, total mass flow rate). This was then used to identify optimal conditions to produce $\alpha$-lactose monohydrate in antisolvent crystallization using continuous mixing-induced supersaturation. 


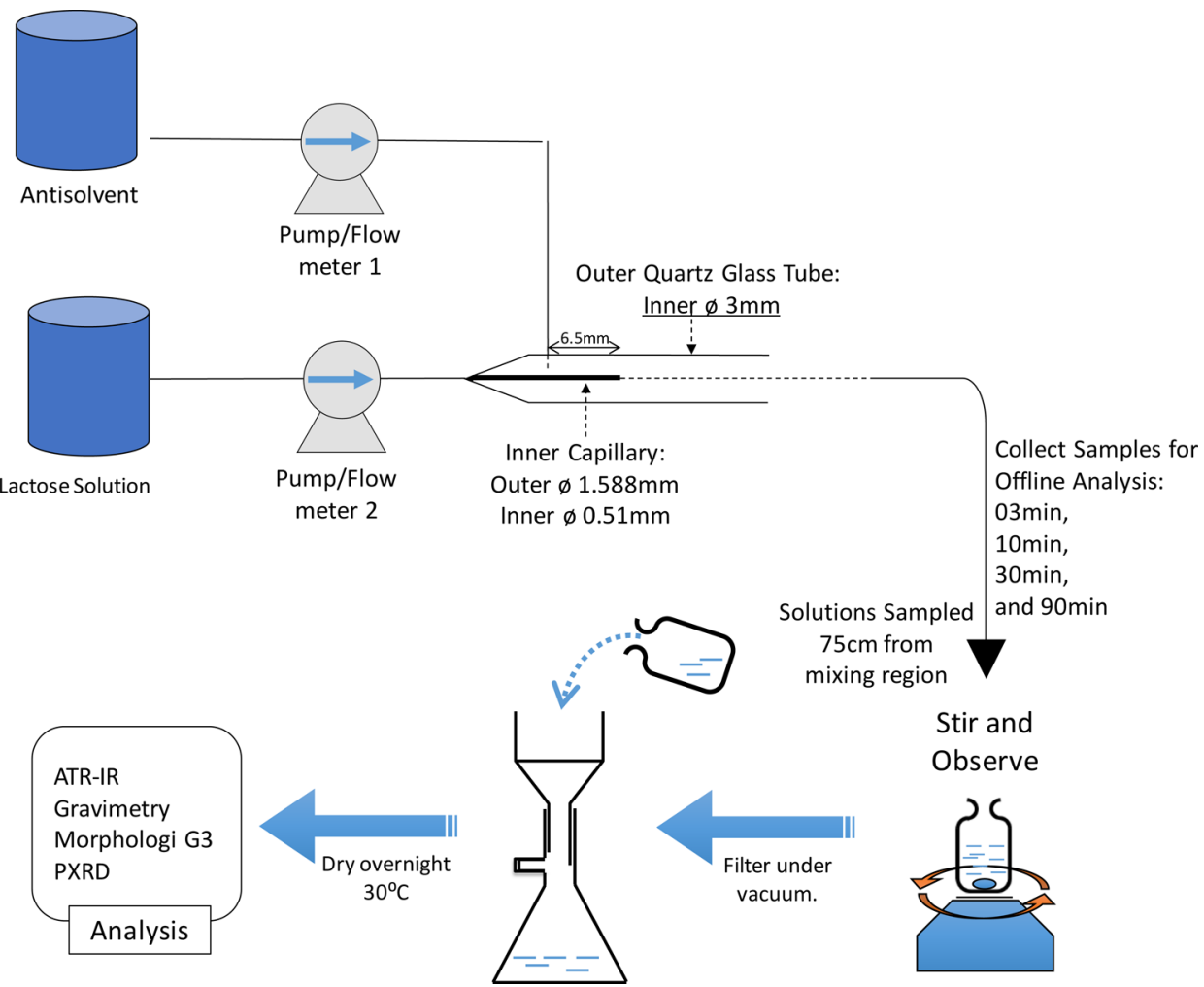

Figure 2. Schematic diagram of experimental setup.

\section{METHODS}

Materials. Isopropanol (IPA) was supplied form Fisher Scientific UK Ltd. (99.5\%; Lot No. 1562431). Acetone (99.8\%; Lot No. STBF6870V) and $\alpha$-lactose monohydrate (99\%; Lot No. SLBK0710V) were supplied from Sigma-Aldrich Company UK Ltd. Water used throughout this work was processed using an Integral 15 Milli-Q water purification system (Merk KGaA) fitted with a Quantum TEX polishing Cartridge.

Solubility Study. Known weights of water and antisolvents mixtures at predetermined compositions were added to vials containing known weights of $\alpha$-lactose monohydrate. These samples were left to stir in an incubator set at $25{ }^{\circ} \mathrm{C}$ for 5,7 , and 11 days to ensure the solution was in equilibrium $(\alpha$-lactose monohydrate and the solvent solution, and $\alpha \leftrightarrow \beta$ mutarotation in solution). These time scales were used in order to ensure that mutarotation of lactose has reached equilibrium in the mixed solvent solutions investigated. Stirring was stopped and left to settle for $5 \mathrm{~h}$ before taking a sample of the mother liquor using a syringe filter $(0.45 \mu \mathrm{m}$ pore size $)$. The filtrate of each sample was weighed, and left to dry in an oven at $60^{\circ} \mathrm{C}$ overnight. The dried samples were weighed to get the weight of the lactose remaining in solution.

Continuous Mixing-Induced Supersaturation. Continuous mixing-induced supersaturation experiments were performed using a concentric capillary mixer (Figure 2). The concentric capillary mixer consists of a polyether-ether-ketonePEEK ) inner capillary with an inner diameter of $0.51 \mathrm{~mm}$ and outer diameter of $1.588 \mathrm{~mm}$, and a quartz glass tube with an inner diameter of $3.0 \mathrm{~mm}$. $\alpha$-lactose monohydrate was dissolved in water at $55{ }^{\circ} \mathrm{C}$ overnight and resulting solutions were left to cool to room temperature $\left(21 \pm 2{ }^{\circ} \mathrm{C}\right)$. The undersaturated feed solutions were pumped and regulated using gear pumps coupled with Bronkhorst Mini-Cori 500 flowmeters. The lactose solution was supplied through the inner capillary, while the antisolvent was fed through the outer glass tube. As the inner capillary was continuously washed by an undersaturated lactose solution, inner capillary blockages were avoided. Under some conditions there was fouling in the outer glass tube and tapping a stainless steel spatula against regions of the outer glass tube that showed fouling reduced subsequent blockages. While some conditions resulted in severe fouling and blockages, under other conditions it was possible to run the process for up to $90 \mathrm{~min}$ without any significant fouling (see Tables SI.1 and SI.2 and images in Supporting Information).

The solution exiting from the mixer was sampled $75 \mathrm{~cm}$ after the end of the capillary at run times of 3, 10, 30, and 90 min, unless fouling or blockage terminated the experiment. In the first set of experiments (DoE1), when comparing acetone and IPA as antisolvents, samples were held under mixing using a magnetic stirrer for $30 \mathrm{~min}$ after collection. In the second set of experiments (DoE2), when further investigating acetone as an antisolvent, samples were held under mixing using a magnetic stirrer for $30 \mathrm{~min}$ after induction time. The purpose of a uniform holding time for all samples across an experimental set (DoE1 or DoE2) was to allow for crystal growth of solid forms present as a result of mixing-induced supersaturation under given mixing conditions. As the holding conditions were identical, any differences in solid forms observed would be resulting from effects of the continuous mixing-induced supersaturation step. After the holding time these samples were filtered under vacuum and dried overnight in an oven at $60{ }^{\circ} \mathrm{C}$. Solid yield was calculated as the percentage of the total lactose mass in the solution prior to crystallization.

Induction times were determined visually on the basis of appearance of turbidity by reviewing images collected by webcam (see Supporting Information). Liquid-liquid phase separation resulting in formation of very fine droplets followed by rapid formation of crystals was noticed under some conditions in preliminary experiments using in situ video microscopy probes, so that induction times reported refer to an onset of phase separation in supersaturated solutions. Induction times were recorded as zero minutes when turbidity was observed at the sampling point while longer times correspond to turbidity being observed during the holding period (see Table 2).

Solid Characterization. Dried solids were analyzed using a Bruker Tensor II ATR-IR with a diamond sample plate, averaging 16 scans of the IR region from 4000 to $450 \mathrm{~cm}^{-1}$, with a resolution of $4 \mathrm{~cm}^{-1}$, using air as a background. The solid states observed were confirmed by comparing experimental powder X-ray diffraction (PXRD) (Bruker AXS DS-Advance, $\mathrm{Cu} \mathrm{K} \alpha 1, \lambda=1.54056 \AA$, $4-35^{\circ}(2 \theta)$ with a $0.016^{\circ}$ 

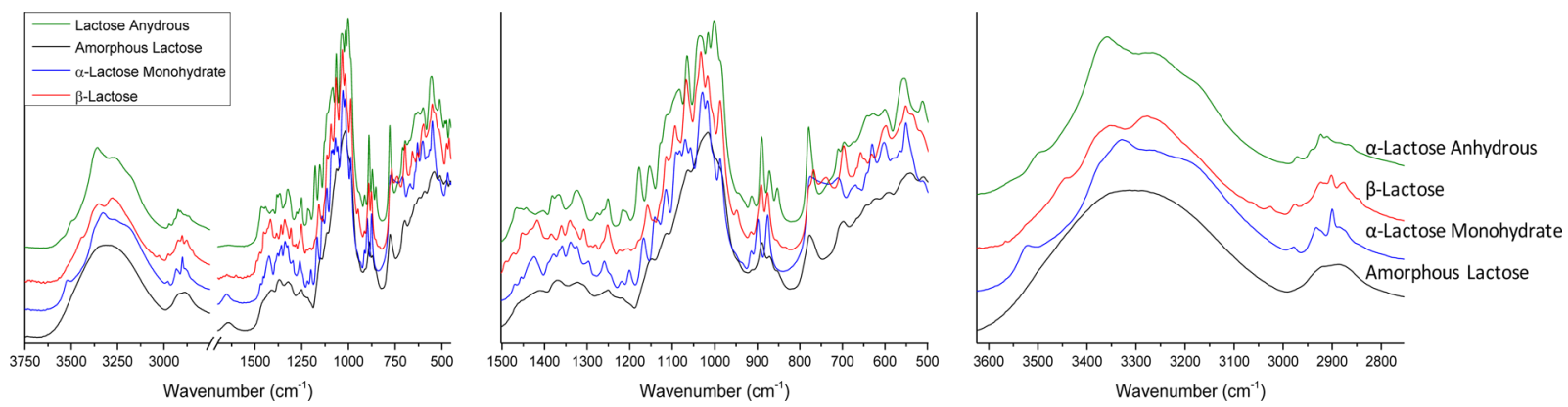

Figure 3. IR spectra of $\alpha$-lactose monohydrate (blue), $\alpha$-lactose anhydrous (green), $\beta$-lactose (red), and amorphous lactose (black).

\section{Experimental}

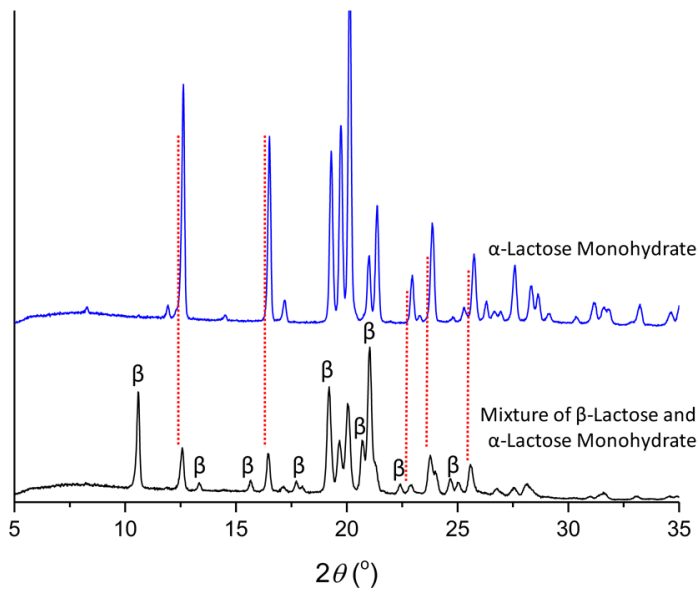

Calculated

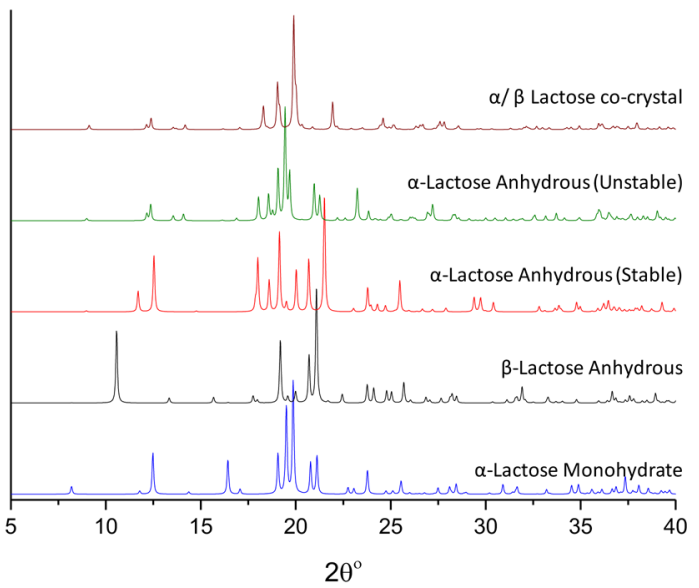

Figure 4. PXRD patterns of recrystallized $\alpha$-lactose monohydrate and $\alpha$-lactose monohydrate/ $\beta$-lactose mixture (left), and calculated powder patterns (right).

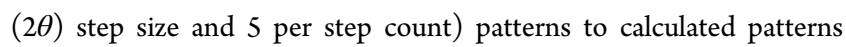
single-crystal data form the Cambridge Crystal Structural Database (CSD). Particle sizing was conducted using a Malvern Morphologi G3, with a $\times 20$ optical zoom, scanning an area of $3.5 \mathrm{~cm} \times 1.5 \mathrm{~cm}$. Number-based mean particle diameter $\left(D_{50}\right)$ and $D_{90}$ were determined on the basis of the equivalent circular diameter.

DoE and Multivariate Analysis. All models were created on a Dell Precision T1650 with an Intel Core i7-3770 CPU $(3.40 \mathrm{GHz})$, with 8 GB RAM running on a 64-bit operating system of Windows 7 Professional Service Pack 1. Umetrics Modde (Version 11, MKS Instruments; Umeå, Sweden) was used to create a DoE sample set and to apply multivariate analysis. A D-optimal method was used to create a sample set that was then analyzed using either multiple linear regression (MLR) or partial least-squares (PLS) methods to measure effects of independent variables on the responses. Principle component analysis (PCA) was used to investigate factor analysis, done using Simca (Version 14, MKS Instruments; Umeå, Sweden).

Two separate DoEs were generated for this study, DoE1 and DoE2. In both DoE studies the parameters (or factors) chosen were the concentration of the lactose solution $\left(0.13-0.21 \mathrm{~g}_{\mathrm{Lac}} / \mathrm{g}_{\mathrm{H}_{2} \mathrm{O}}\right)$, the total mass flow rate $(25-100 \mathrm{~g} / \mathrm{min})$, and the mass flow ratio of the lactose solution and the antisolvent. The first $\mathrm{DoE}$ (DoE1) was to compare the two antisolvents (IPA and acetone), an additional parameter in this study, and used the mass flow ratios ranging 1:1-1:9 (g/min $\operatorname{macSol}_{\mathrm{l}}: \mathrm{g} /$ $\left.\min _{\text {Antisol. }}\right)$, resulting in antisolvent mass flow fractions between 0.5 and 0.9. The responses analyzed for DoE1 were the solid state of lactose, the mean particle diameter, $D_{90}$, and solid yield. Taking samples at different time intervals produced up to four samples for each experimental run. All were analyzed using ATR-IR and gravimetry. Particle sizes were only determined for one sample (at $30 \mathrm{~min}$ or the last sample taken before blockage) for each run. ATR-IR results showed that the solid state was the same at all sampling times for each run. Spectra acquired at $30 \mathrm{~min}$ were used for PCA analysis (see Figure 6). Average yields and corresponding errors from up to four measurements are shown in Tables SI.1 and SI.2 in Supporting Information. The other DoE (DoE2) work was to generate a higher resolution of the response surface for the preferred antisolvent (acetone), and included the mass flow ratios 2:3 and 3:2 ( $\mathrm{g} / \mathrm{min}_{\mathrm{Lac} . \mathrm{Sol}}$ : $\mathrm{g} / \mathrm{min}_{\text {Antisol. }}$. DoE2 was designed to better investigate the factors and design space regions that gave a better model. Using this model an optimized process was generated to crystallize $\alpha$-lactose monohydrate. This optimized process was tested experimentally to validate the model.

\section{RESULTS}

Preparation and Characterization of Lactose Solid States. In this study four solid states of lactose were observed; $\alpha$-lactose monohydrate, $\alpha$-lactose anhydrous, $\beta$-lactose, and amorphous lactose. Though it is possible that the $\alpha / \beta$ co-crystal was produced as a transient phase it was not detected from PXRD or IR data. Reference samples of $\alpha$-lactose monohydrate were recrystallized from water and used to collect reference IR spectra and PXRD patterns. ${ }^{12,48}$ Amorphous lactose was prepared via melt quench and used to identify amorphous content. A $0.3 \mathrm{~g}$ sample of $\alpha$-lactose monohydrate was heated to $225{ }^{\circ} \mathrm{C}$ and cooled to room temperature within $4 \mathrm{~min} . \alpha$ Lactose anhydrous (stable) was produced by heating $\alpha$-lactose monohydrate to $160{ }^{\circ} \mathrm{C}$ and left to cool, the IR spectrum of the dehydrated sample compared well to those in literature. ${ }^{12}$ The unstable form $\alpha$-lactose anhydrous was not detected in this work. $\beta$-lactose was prepared by sonicating a mixture of $2.5 \mathrm{~mL}$ of IPA and $2.5 \mathrm{~mL}$ of a lactose solution $\left(0.185 \mathrm{~g}_{\mathrm{Lac}} / \mathrm{g}_{\mathrm{H}_{2} \mathrm{O}}\right)$ for 60 


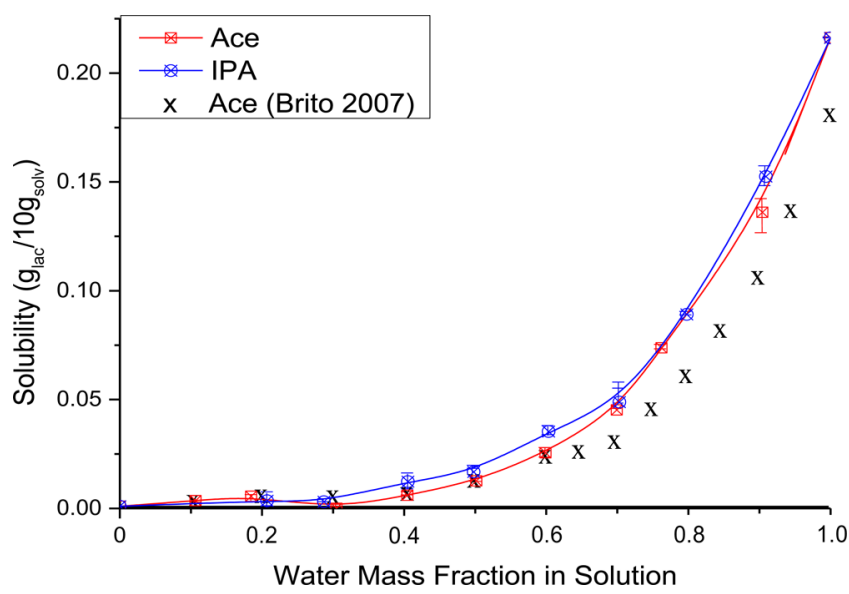

Figure 5. Solubility curve of lactose (starting from slurries of $\alpha$-lactose monohydrate) in acetone (red) and IPA (blue), and results from previous literature for acetone $(\times)$.

Table 1. Results of DoE1 Runs for IPA and Acetone as Antisolvent $^{a}$

\begin{tabular}{|c|c|c|c|c|c|}
\hline antisolvent & $\begin{array}{l}\text { mass flow } \\
\text { fraction of } \\
\text { antisolvent }\end{array}$ & $\begin{array}{c}\text { concentration } \\
\text { of lactose } \\
\left(\mathrm{g}_{\mathrm{Lac}} / \mathrm{g}_{\mathrm{H}_{2} \mathrm{O}}\right)\end{array}$ & $\begin{array}{l}\text { overall } \\
\text { flow rate } \\
(\mathrm{g} / \mathrm{min})\end{array}$ & $\begin{array}{l}\text { solid } \\
\text { state } \\
\text { index }\end{array}$ & $\begin{array}{c}\text { solid } \\
\text { yield } \\
(\%)\end{array}$ \\
\hline IPA & 0.9 & 0.144 & 25 & 0.315 & 80 \\
\hline acetone & 0.5 & 0.118 & 50 & 0.953 & 20 \\
\hline IPA & 0.5 & 0.133 & 100 & 0.071 & 5 \\
\hline IPA & 0.5 & 0.130 & 25 & 0.120 & 15 \\
\hline acetone & 0.75 & 0.132 & 25 & 0.057 & 45 \\
\hline acetone & 0.9 & 0.134 & 25 & 0.443 & 42 \\
\hline acetone & 0.9 & 0.214 & 25 & 0.754 & 80 \\
\hline acetone & 0.75 & 0.161 & 50 & 0.692 & 89 \\
\hline IPA & 0.75 & 0.159 & 50 & 0.558 & 57 \\
\hline IPA & 0.75 & 0.159 & 50 & 0.443 & 40 \\
\hline IPA & 0.75 & 0.159 & 50 & 0.434 & 42 \\
\hline IPA & 0.75 & 0.159 & 50 & 0.435 & 40 \\
\hline acetone & 0.50 & 0.161 & 25 & 0.833 & 8 \\
\hline acetone & 0.6 & 0.161 & 50 & 0.761 & 63 \\
\hline acetone & 0.5 & 0.132 & 25 & 0.125 & 6 \\
\hline IPA & 0.9 & 0.214 & 25 & 0.303 & 90 \\
\hline acetone & 0.5 & 0.134 & 100 & 0.914 & 5 \\
\hline acetone & 0.6 & 0.217 & 25 & 0.487 & 58 \\
\hline acetone & 0.6 & 0.131 & 100 & 0.884 & 35 \\
\hline acetone & 0.6 & 0.217 & 100 & 0.807 & 73 \\
\hline IPA & 0.5 & 0.134 & 25 & 0.123 & 18 \\
\hline acetone & 0.5 & 0.214 & 25 & 0.839 & 15 \\
\hline IPA & 0.5 & 0.214 & 25 & 0.851 & 11 \\
\hline acetone & 0.5 & 0.1367 & 100 & 0.910 & 25 \\
\hline IPA & 0.9 & 0.134 & 100 & 0.298 & 60 \\
\hline IPA & 0.9 & 0.161 & 100 & 0.289 & 78 \\
\hline acetone & 0.5 & 0.214 & 100 & 0.851 & 23 \\
\hline IPA & 0.5 & 0.214 & 100 & 0.861 & 11 \\
\hline IPA & 0.9 & 0.214 & 100 & 0.298 & 50 \\
\hline acetone & 0.6 & 0.131 & 25 & 0.877 & 9 \\
\hline
\end{tabular}

${ }^{a}$ Additional information is given in Supporting Information Table SI.1.

min at a constant frequency of $80 \mathrm{~Hz}$ and $100 \mathrm{~W}$ of power. $\beta$ Lactose crystallized as small thin needles and was confirmed as $\beta$-lactose using ATR-IR.

Characteristic peaks of each lactose solid state can be seen in the IR fingerprint region $\left(1500-500 \mathrm{~cm}^{-1}\right)$ as well the first octave $\left(2717-3588 \mathrm{~cm}^{-1}\right)$, most notably showing a peak shift from the $\mathrm{O}-\mathrm{H}$ bond vibrations (Figure 3). This peak shifts from $3445 \mathrm{~cm}^{-1}$ for $\beta$-lactose to $3470 \mathrm{~cm}^{-1}$ for anhydrous lactose, and $3520 \mathrm{~cm}^{-1}$ for $\alpha$-lactose monohydrate. The amorphous phase shows a broadening of all peaks in this region creating a single broad peak at $3300 \mathrm{~cm}^{-1}$. In the fingerprint region, amorphous lactose possesses characteristic peaks at 1370,1150 , and $890 \mathrm{~cm}^{-1} ; \beta$-lactose has a peak at 950 $\mathrm{cm}^{-1} ; \alpha$-lactose anhydrous has a noticeable singlet at 1325 $\mathrm{cm}^{-1}$; and $\alpha$-lactose monohydrate has unique peaks at 1201 and $1167 \mathrm{~cm}^{-1}$. These differences in the spectra make IR an accurate and robust method to detect and identify the solid state of lactose.

PXRD confirmed the solids states of the lactose being crystallized in experiments comparing IPA and acetone as antisolvents. Powder patterns of experimental samples of $\alpha$ lactose monohydrate and a mixed sample of $\alpha$-lactose monohydrate and $\beta$-lactose were compared to patterns calculated from their corresponding CIF files obtained from the Cambridge Structural Database (LACTOS01 ${ }^{49}$ and BLACT002 ${ }^{50}$ respectively) using Mercury 3.8 (Figure 4). Pure $\beta$-lactose could not be produced in adequate quantities so comparisons using a mixed sample of $\alpha$-lactose monohydrate and $\beta$-lactose was done. Peaks for $\alpha$-lactose anhydrous were compared to those reported by Platteau et al. in 2004 and 2005 (EYOCUQ $^{51}$ and EYOCUQ01 ${ }^{52}$ ), and LAKKEO for the $\alpha / \beta$ co-crystal at $20{ }^{\circ} \mathrm{C} .{ }^{53}$ The amorphous hump and an increased baseline showed the presence of amorphous lactose which at times contained partial content of $\alpha$-lactose anhydrous.

Comparing IPA and Acetone as Antisolvents. In Figure 5 we compare the solubility of $\alpha$-lactose monohydrate measured in mixtures of water and acetone or IPA. These curves are the average of equilibrium composition for solutions that were held for 5, 7, and 11 days. Deviations from the curve were unbiased with regard to the length of time being held indicating that equilibrium had been reached.

Using a D-optimal model in the Modde 11 software a sample set of 27 continuous crystallization experiments containing 3 repeats was generated for DoE1. The parameters investigated were the choice of antisolvent (acetone or IPA), total mass flow rate, the mass flow ratio of the lactose solution and antisolvent, and the concentration of the lactose solution. Varying these parameters was found to produce either solid state mixtures of $\alpha$-lactose monohydrate and $\beta$-lactose, $\alpha$-lactose anhydrous, or pure $\alpha$-lactose monohydrate. Though both antisolvents show similar lactose solubilities, different solid states of lactose were obtained for similar conditions using different antisolvents.Table 1 shows the results of experiments from DoE1.

IR spectral data of the samples were pre-processed using Standard Normal Variate (SNV) and projected onto a scores plot using PCA (Figure 6). SNV corrected for baseline offset and reduced background noise. The SNV transformed data from regions between 3585 and $2767 \mathrm{~cm}^{-1}$, and between 1505 and $830 \mathrm{~cm}^{-1}$, were projected onto a PCA model clustering samples with similar spectral information together. Information from this model created an index relating the coordinates of the samples to coordinates of commercial $\alpha$-lactose monohydrate shown in Figure 6. By determining the center of mass of the samples and using it as a center point, an angular position of samples was used to group different solid states of lactose. The angular position of a sample was used as an index to express the $\alpha$-lactose monohydrate content in that sample. This index gives a single variable running from 0 to 1 . Samples that gave results of $0.8-1$ were considered pure $\alpha$-lactose monohydrate. 


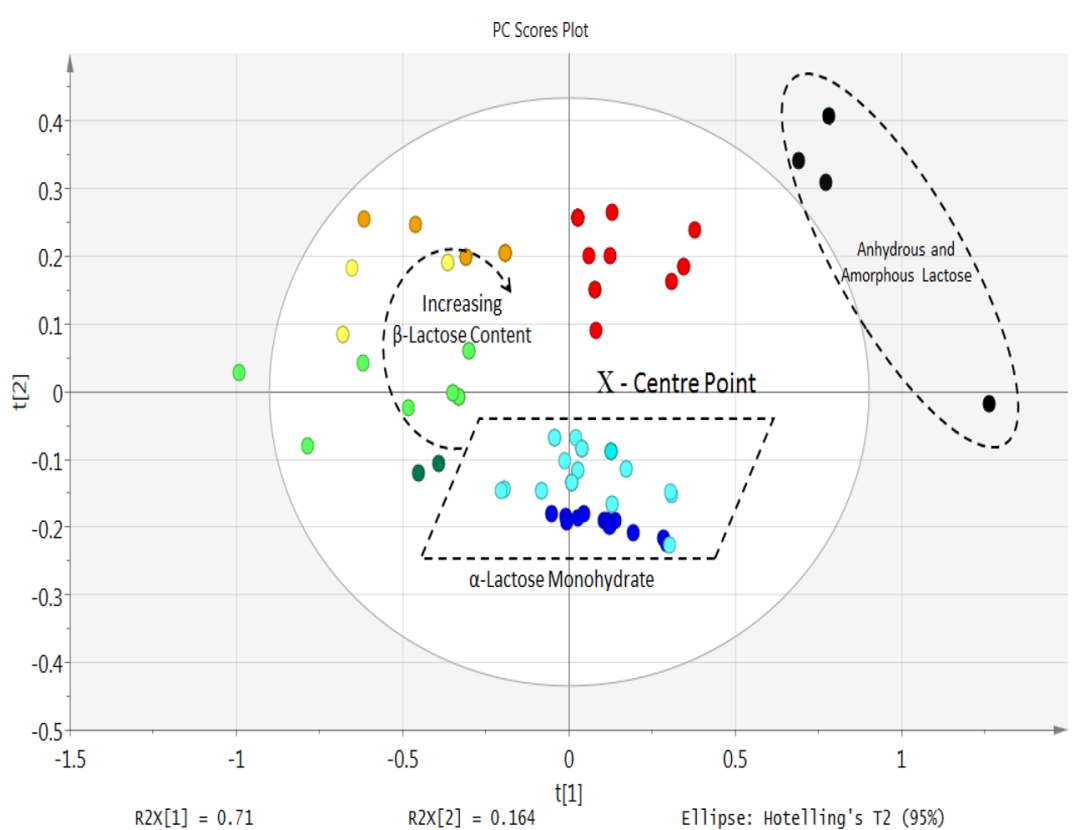

Figure 6. Scores plot of the solid states crystallized from DoE experiments. Dark blue dots indicate commercial $\alpha$-lactose monohydrate.
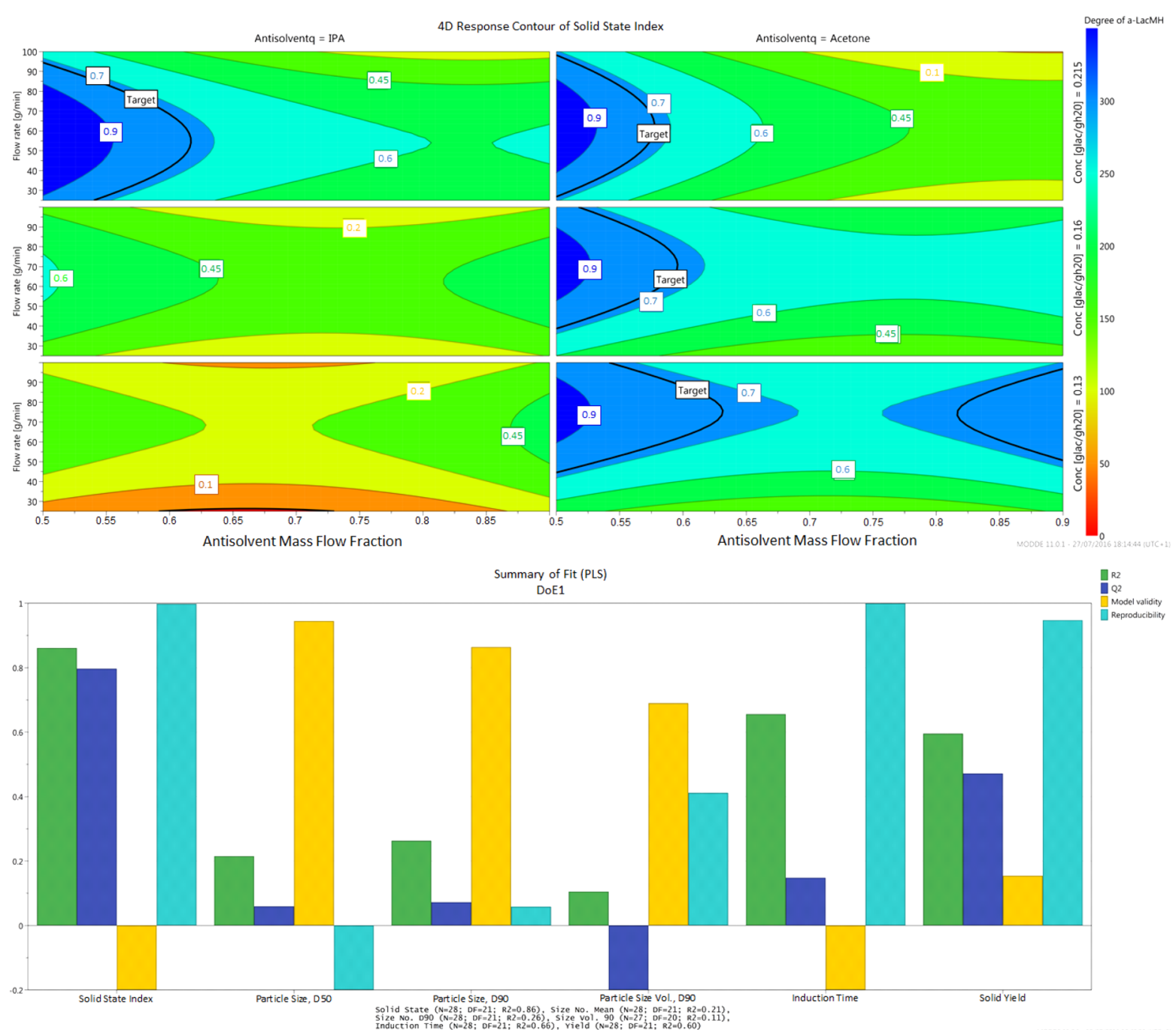

Figure 7. Response surface of solid state index (top) and summary of fit (bottom) using data from DoE1. 


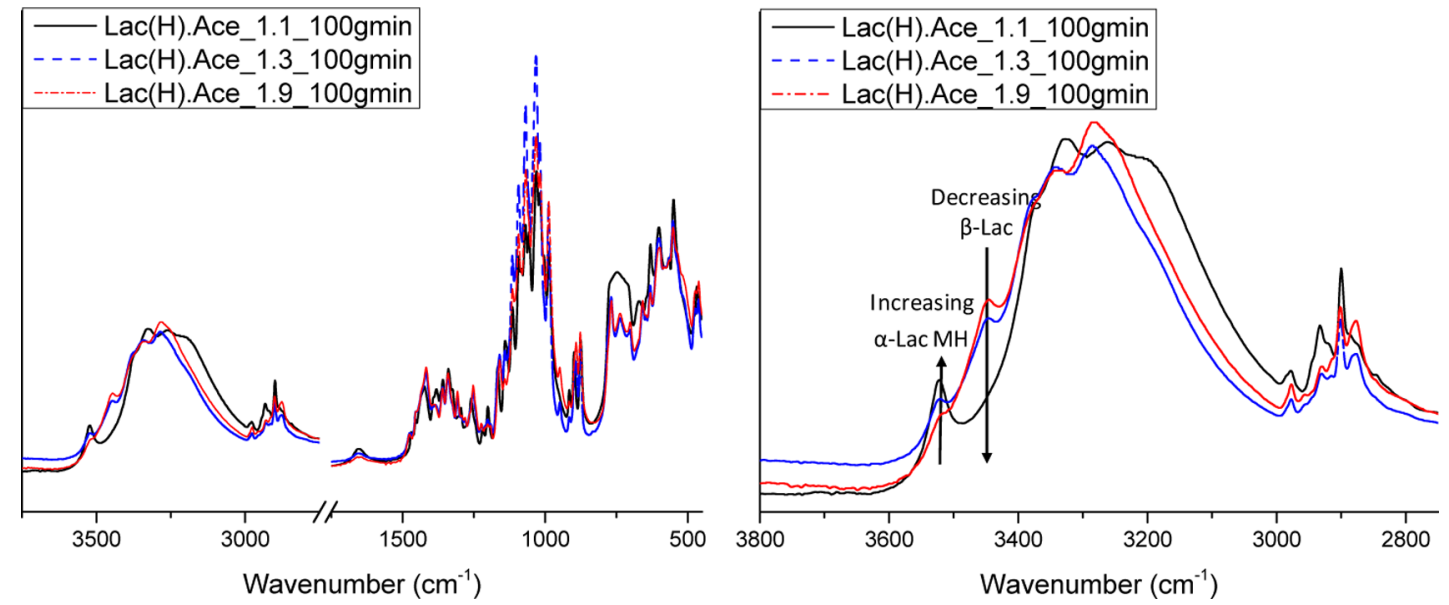

Figure 8. IR spectra of increasing $\beta$-lactose content in mixtures with $\alpha$-lactose monohydrate using the mass flow ratios 1:1 ( $\cdots)$, 1:3(---), and 1:9 $(--)$ ( $\left.\mathrm{g}_{\text {LacSoln. }} / \mathrm{min}: \mathrm{g}_{\text {Antisolv. }} / \mathrm{min}\right)$.

Table 2. Results of DoE2 Runs for Acetone as Antisolvent ${ }^{a}$

$\begin{array}{cccccc}\begin{array}{c}\text { mass flow } \\ \text { fraction of } \\ \text { acetone }\end{array} & \begin{array}{c}\text { concentration of } \\ \text { lactose solution } \\ \left(\mathrm{g}_{\text {lac }} / \mathrm{g}_{\mathrm{H}_{2} \mathrm{O}}\right)\end{array} & \begin{array}{c}\text { total mass } \\ \text { flow rate } \\ (\mathrm{g} / \mathrm{min})\end{array} & \begin{array}{c}\text { solid } \\ \text { state } \\ \text { index }\end{array} & \begin{array}{c}\text { induction } \\ \text { time } \\ (\mathrm{min})\end{array} & \begin{array}{c}\text { solid } \\ \text { yield } \\ (\%)\end{array} \\ 0.4 & 0.213 & 100 & 0.832 & 30 & 12 \\ 0.4 & 0.132 & 100 & 0.857 & 330 & 53 \\ 0.4 & 0.169 & 50 & 0.875 & 70 & 53 \\ 0.4 & 0.217 & 25 & 0.857 & 27 & 25 \\ 0.4 & 0.132 & 25 & 0.858 & 170 & 9 \\ 0.5 & 0.215 & 100 & 0.876 & 0.5 & 20 \\ 0.5 & 0.131 & 100 & 0.912 & 15 & 31 \\ 0.5 & 0.132 & 50 & 0.851 & 25 & 10 \\ 0.5 & 0.164 & 50 & 0.849 & 9 & 22 \\ 0.5 & 0.164 & 50 & 0.867 & 10 & 26 \\ 0.5 & 0.163 & 50 & 0.843 & 10.5 & 9 \\ 0.5 & 0.214 & 25 & 0.864 & 9 & 10 \\ 0.5 & 0.113 & 25 & 0.854 & 75 & 8 \\ 0.5 & 0.164 & 25 & 0.865 & 19 & 21 \\ 0.6 & 0.218 & 100 & 0.831 & 0 & 76 \\ 0.6 & 0.132 & 100 & 0.888 & 0 & 31 \\ 0.6 & 0.164 & 100 & 0.909 & 0 & 24 \\ 0.6 & 0.164 & 100 & 0.877 & 0 & 37 \\ 0.6 & 0.217 & 50 & 0.859 & 0 & 40 \\ 0.6 & 0.161 & 50 & 0.855 & 12 & 37 \\ 0.6 & 0.218 & 25 & 0.488 & 3 & 69 \\ 0.6 & 0.131 & 25 & 0.860 & 5 & 38 \\ 0.6 & 0.132 & 25 & 0.849 & 6 & 34 \\ 0.75 & 0.161 & 50 & 0.306 & 0 & 60 \\ 0.75 & 0.132 & 25 & 0.488 & 0 & 54 \\ 0.9 & 0.214 & 100 & 0.049 & 0 & 87 \\ 0.9 & 0.133 & 0.126 & 0 & 78 \\ 0.9 & 0.134 & 0.153 & 0 & 75 \\ 0.9 & 0.25 & 0.153 & 0 & 84\end{array}$

${ }^{a}$ Additional information is given in Supporting Information Table SI.2.

Samples with an index from 0.25 to 0.8 contained $\beta$-lactose, with a lower value corresponding to higher $\beta$-lactose content, and samples with an index $<0.25$ were predominantly $\alpha$-lactose anhydrous or amorphous lactose. This index value was used to create a response surface map using PLS methods.

Based on the results from DoE1, the major parameters found to affect the solid state were the mass flow rate ratio of the antisolvent and lactose solutions, and the concentration of the lactose solution. Total mass flow rate was found to only play a part in the generation of anhydrous or amorphous lactose, most likely due to poor mixing at lower total mass flow rates. Though little change could be observed in the particle size, some change could be seen in the solid yield. Yield was influenced by mass flow ratio but not the lactose solution concentration. This data was analyzed by Modde to create a well fitted model having high $R^{2}$ (the amount of the variation of the response explained by the model) that presented discernible patterns. These patterns could be modeled using PLS having high $R^{2}$ but having a low model validity of $>0.25$. The $Q^{2}$ value (the amount of the variation of the response predicted by the model according to cross validation) across every factor was at -0.2 , showing the overall model cannot be used to predict outcomes with great confidence (Figure 7)

The IR data show increased amounts of $\beta$-lactose were crystallized along with $\alpha$-lactose monohydrate when using greater mass flow ratio of IPA or acetone, with samples using IPA showing more $\beta$-lactose content than their acetone counterparts (Figure 8). Pure $\alpha$-lactose monohydrate was crystallized from samples from 1:1 mass flow ratios of lactose solutions and acetone. Amorphous lactose and mixtures of anhydrous and amorphous lactose were produced in experiments using low concentrations of lactose $\left(0.135 \mathrm{~g}_{\text {lac }} / \mathrm{g}_{\mathrm{H}_{2} \mathrm{O}}\right)$, low total mass flow rates $(25 \mathrm{~g} / \mathrm{min})$, and mass flow ratios of $1: 1$. Though too little product could be collected from these samples to carry out PXRD, there was enough for IR analysis. Amorphous lactose solidified as a hard brittle glass, and $\alpha$ lactose anhydrous crystallized as white solid. Samples that crystallized $\beta$-lactose crystallized instantly or within $30 \mathrm{~s}$ after collection. Samples that produced high amorphous content or $\alpha$-lactose anhydrous had longer induction times.

Acetone as Antisolvent. From DoE1 when comparing acetone and IPA as antisolvents, it can be seen that using acetone near the 1:1 mass flow ratio is most favored to produce $\alpha$-lactose monohydrate. Therefore, further analysis focused on finding an optimized process with acetone as the antisolvent. The design space was extended to consider using mass flow ratios near $1: 1$ to explore conditions to crystallize pure $\alpha$ lactose monohydrate. The mass flow ratios chosen were $2: 3$, $1: 1$, and $3: 2\left(\mathrm{~g} / \mathrm{min}_{\text {Lac.Soln. }} \mathrm{g} / \mathrm{min}_{\text {Antisolv. }}\right)$, and relevant data from previous experiments were included. Induction time was also 

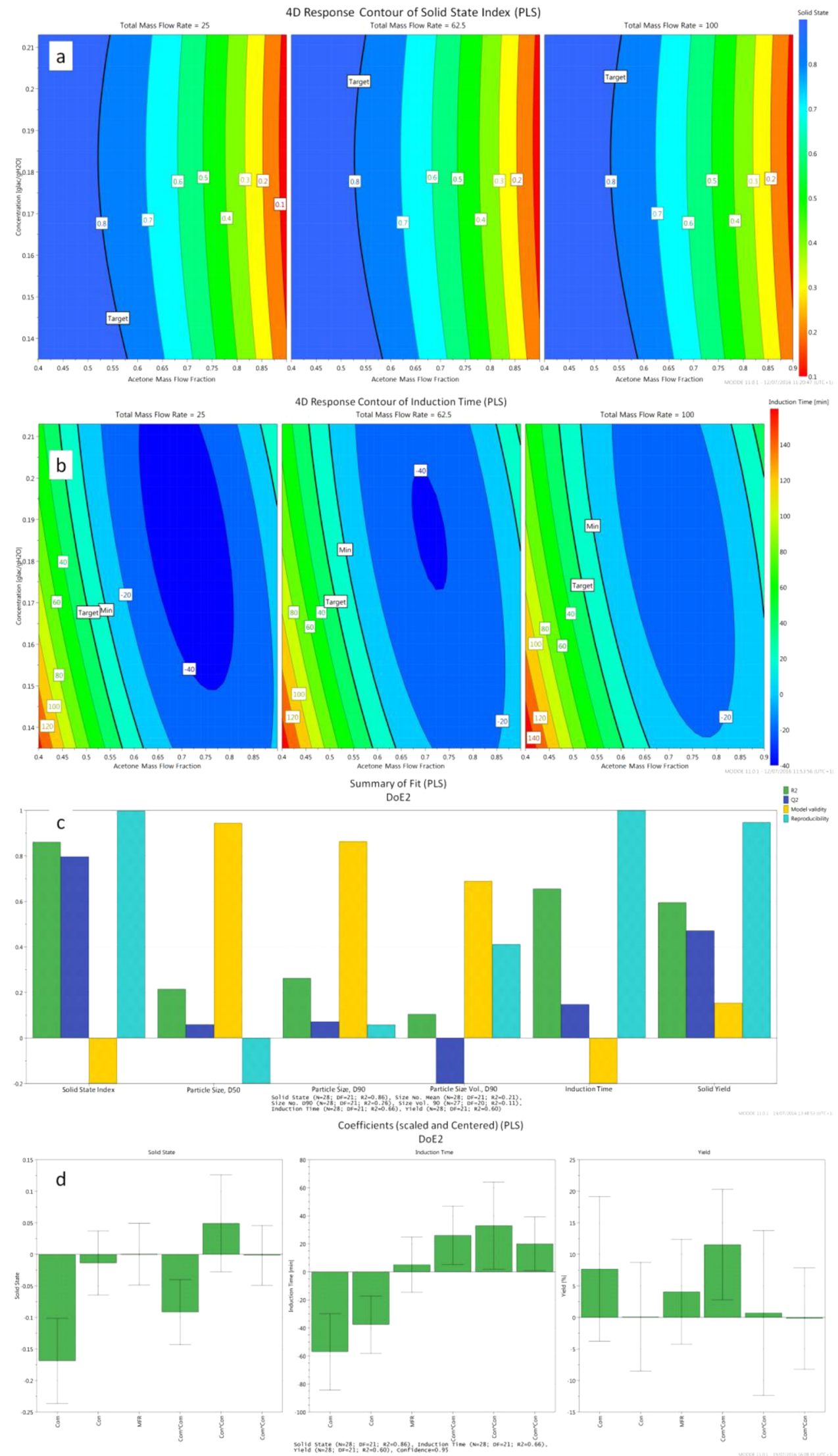

Figure 9. Response surface of solid state index (a) and induction time (b), summary of fit (c), and effect of coefficient (d) using data from DoE2.

added as a response. Table 2 shows the results of experiments from DoE2.
Trends were found correlating the antisolvent/lactose solution mass flow ratio to the induction times observed 


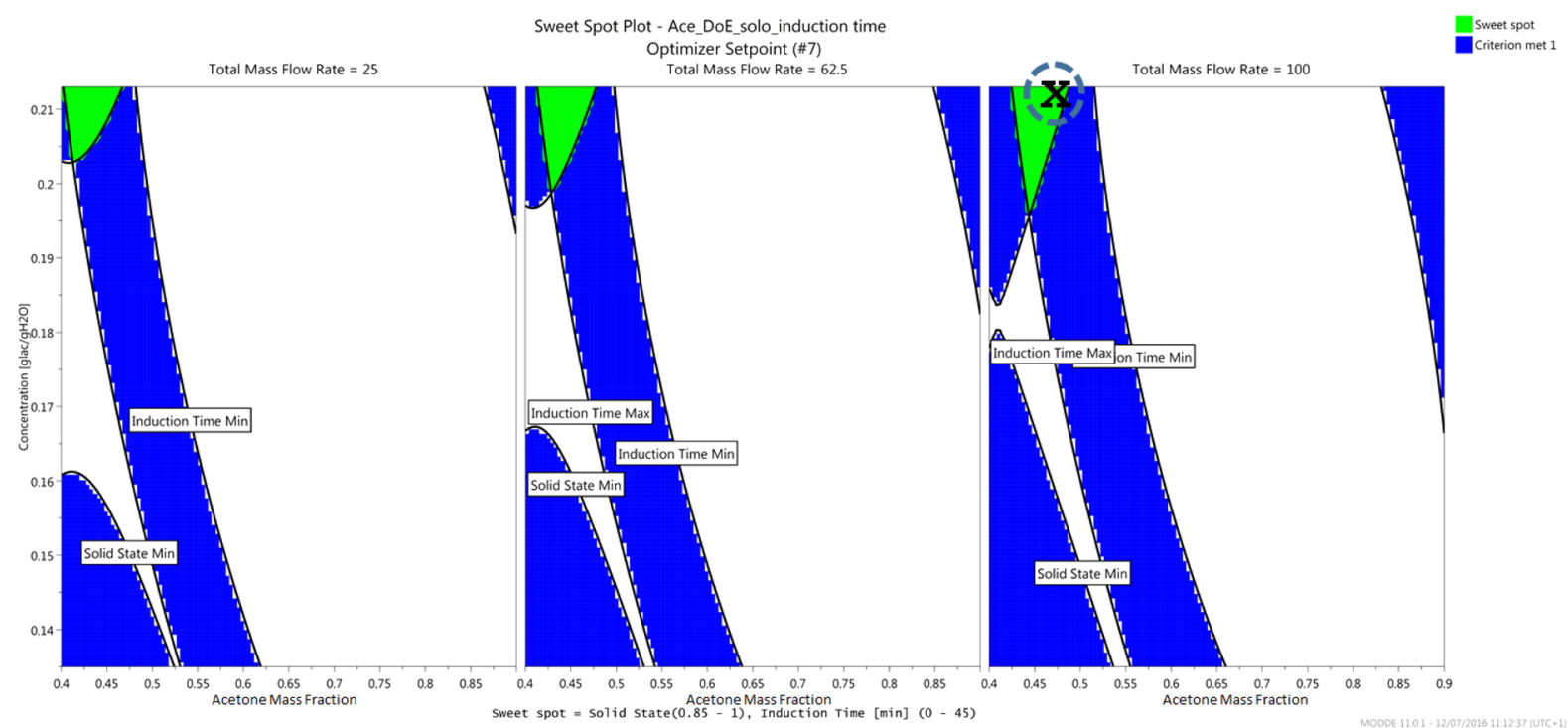

Figure 10. Sweet spot diagram, with "X" showing the region in the space diagram to produce $\alpha$-lactose monohydrate with the lowest induction time and highest yield.

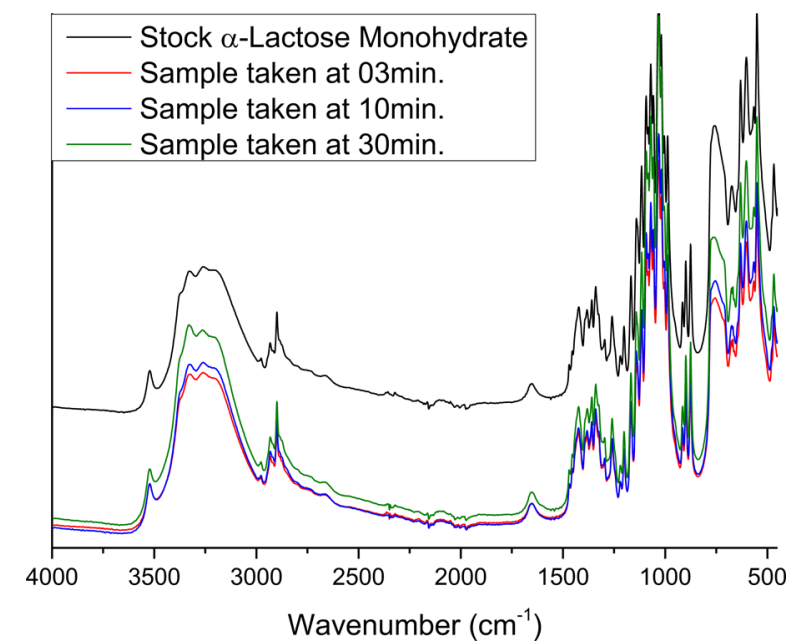

Figure 11. IR spectra of solid samples from optimized process conditions.

(Supporting Information, Figure S2). Due to changes in induction time samples were filtered $30 \mathrm{~min}$ after particles were visually observed in the images recorded. Induction time was found to decrease with increased antisolvent and with higher lactose concentration solution. Changes in induction time showed variation in yield, but again little change was observed in particle size. Since the mass flow ratio was found to influence induction time, yield can be increased by allowing the $\alpha$-lactose monohydrate crystals to grow over time.

By removing IPA as an antisolvent and using only acetone the model became much more accurate and reliable, with a $\mathrm{R}^{2}$ and $\mathrm{Q}^{2}$ above 0.8 for the solid state, increasing the confidence of the model (Figure 9). It is clear that mass flow ratio is the most important parameter in crystallization control. Because calculated validity was low, the model was validated experimentally.

The model was used to create an optimized set of parameters to crystallize pure $\alpha$-lactose monohydrate, having low induction time and high yield. The optimized process (Figure 10) was predicted as follows: using a near saturated lactose solution of
$0.213 \mathrm{~g}_{\mathrm{Lac}} / \mathrm{g}_{\mathrm{H}_{2} \mathrm{O}}$, mass flow ratio of $19: 21$ ( $\mathrm{g} / \mathrm{min}_{\mathrm{LacSol}}: \mathrm{g} /$ $\min _{\text {Ace }}$ ), and a total mass flow rate of $85 \mathrm{~g} / \mathrm{min}$. Using this model, the following prediction were made; the solid form crystallized will be pure $\alpha$-lactose monohydrate, having an induction time $<7 \mathrm{~min}$, mean particle diameter $19.5 \mu \mathrm{m}, D_{90}$ of $50.0 \mu \mathrm{m}$, and a solid yield of $35 \%$.

The final product, pure $\alpha$-lactose monohydrate (Figure 11), had an induction time of $<2 \mathrm{~min}$, a mean particle diameter 38.5 $\mu \mathrm{m}( \pm 4.5 \mu \mathrm{m}), D_{90}$ of $90.1 \mu \mathrm{m}( \pm 10.7 \mu \mathrm{m})$, and yield averaging $33.2 \%( \pm 5.6 \%)$. The solid state crystallized and yield agreed very well with the model, and to a lesser extent induction time, whereas particle size was not predicted accurately.

\section{CONCLUSIONS}

Using a multivariate approach to DoE the effects of key process parameters of continuous mixing-induced supersaturation on the antisolvent crystallization of lactose were quantitatively evaluated. Information from the initial set of experiments (DoE1) comparing IPA and acetone as antisolvents was used to design the second set of experiments (DoE2) in order to develop a model to identify conditions that would be best to crystallize pure $\alpha$-lactose monohydrate using acetone. The response surface of the solid state index gave a predictive crystallization diagram for the solid states of lactose. Based on this, an optimized set of parameters were found for the crystallization of $\alpha$-lactose monohydrate. Predictions from the model agreed well with those obtained experimentally, with solid state, yield, and induction time accurately predicted.

\section{ASSOCIATED CONTENT}

\section{S Supporting Information}

The Supporting Information is available free of charge on the ACS Publications website at DOI: 10.1021/acs.cgd.7b00136.

Detailed results of the DoE models including mean particle size, D90, and process notes on the experiments; images showing fouling and blockage, sweet spot and failure rate of optimized system, and induction time (PDF) 


\section{AUTHOR INFORMATION}

\section{Corresponding Author}

*E-mail: jan.sefcik@strath.ac.uk.

\section{ORCID $\odot$}

Pól MacFhionnghaile: 0000-0001-6145-8646

Vaclav Svoboda: 0000-0002-2386-7112

\section{Notes}

The authors declare no competing financial interest.

\section{ACKNOWLEDGMENTS}

The authors would like to thank EPSRC Doctoral Training Centre in Continuous Manufacturing and Crystallization (grant EP/K503289/1), and EPSRC Centre for Innovative Manufacturing in Continuous Manufacturing and Crystallization (grant $\mathrm{EP} / \mathrm{I033459/1)}$ for funding this work. The authors acknowledge that this work was carried out in the CMAC National Facility, supported by a UK Research Partnership Fund award from the Higher Education Funding Council for England (grant HH13054).

\section{REFERENCES}

(1) Wong, S. Y.; Hartel, R. W. Crystallization in Lactose Refining-A Review. J. Food Sci. 2014, 79 (3), R257-R272.

(2) Gekas, V.; Lopezleiva, M. Hydrolysis of Lactose - A Literature Review. Process Biochem. 1985, 20 (1), 2-12.

(3) Keenan, T.; Morré, D. J.; Cheetham, R. Lactose synthesis by a Golgi apparatus fraction from rat mammary gland. Nature 1970, 228 (5276), 1105-1106.

(4) Reiss, O. K.; Barry, J. M. The synthesis of lactose from glucose in the mammary gland. Biochem. J. 1953, 55 (5), 783-785.

(5) Brew, K.; Vanaman, T. C.; Hill, R. L. Role of alpha-Lactalbumin and a Protein in Lactose Synthetase - A Unique Mechanism for Control of a Biological Reaction. Proc. Natl. Acad. Sci. U. S. A. 1968, 59 (2), 491-497.

(6) Crisp, J. L.; Dann, S. E.; Blatchford, C. G. Antisolvent crystallization of pharmaceutical excipients from aqueous solutions and the use of preferred orientation in phase identification by powder X-ray diffraction. Eur. J. Pharm. Sci. 2011, 42 (5), 568-577.

(7) Bolhuis, G. K.; Reichman, G.; Lerk, C. F.; Van Kamp, H. V.; Zuurman, K. Evaluation of Anhydrous $\alpha$-Lactose, A New Excipient in Direct Compression. Drug Dev. Ind. Pharm. 1985, 11 (8), 1657-1681.

(8) Garnier, S.; Petit, S.; Mallet, F.; Petit, M. N.; Lemarchand, D.; Coste, S.; Lefebvre, J.; Coquerel, G. Influence of ageing, grinding and preheating on the thermal behaviour of $\alpha$-lactose monohydrate. Int. J. Pharm. 2008, 361 (1-2), 131-140.

(9) Paterson, A. H. J.; Brooks, G. F.; Bronlund, J. E.; Foster, K. D. Development of stickiness in amorphous lactose at constant $\mathrm{T}-\mathrm{Tg}$ levels. Int. Dairy J. 2005, 15 (5), 513-519.

(10) Haase, G.; Nickerson, T. A. Kinetic Reactions of Alpha and Beta Lactose. II. Crystallization1. J. Dairy Sci. 1966, 49 (7), 757-761.

(11) Haase, G.; Nickerson, T. A. Kinetic Reactions of Alpha and Beta Lactose. I. Mutarotation1. J. Dairy Sci. 1966, 49 (2), 127-132.

(12) Drapier-Beche, N.; Fanni, J.; Parmentier, M. Physical and Chemical Properties of Molecular Compounds of Lactose. J. Dairy Sci. 1999, 82 (12), 2558-2563.

(13) Fox, P. F.; McSweeney, P. L. H. Dairy Chemistry and Biochemistry; Kluwer Academic/Plenum Publishers: New York, 1998.

(14) Raghavan, S. L.; Ristic, R. I.; Sheen, D. B.; Sherwood, J. N.; Trowbridge, L.; York, P. Morphology of Crystals of $\alpha$-Lactose Hydrate Grown from Aqueous Solution. J. Phys. Chem. B 2000, 104 (51), 12256-12262.

(15) Patel, K. N.; Nickerson, T. A. Influence of Sucrose on the Mutarotation Velocity of Lactose. J. Dairy Sci. 1970, 53 (12), 16541658.

(16) Dincer, T. D.; Parkinson, G. M.; Rohl, A. L.; Ogden, M. I. Crystallisation of $\alpha$-lactose monohydrate from dimethyl sulfoxide
(DMSO) solutions: influence of $\beta$-lactose. J. Cryst. Growth 1999, 205 (3), 368-374.

(17) Bell, R. W. Free water necessary to change beta lactose hydrous to alpha lactose anhydrous. Ind. Eng. Chem. 1930, 22, 379-380.

(18) Gillis, J. De oplosbaarheid van lactose in pyridine. Natuurw. Tijdschr. 1930, 12 (5), 171-178.

(19) Verschuur, R. Le Changement de la Rotation et du Pouvoir Conducteur de Quelques Sucres en Solution Aqueuse avec et Sans Acide Borique, I. Recl Trav. Chim. Pays-Bas 1928, 47 (2), 123-152.

(20) Whittier, E. O. Lactose and its Utilization: A Review. J. Dairy Sci. 1944, 27 (7), 505-537.

(21) Figura, L. O. The physical modification of lactose and its thermoanalytical identification. Thermochim. Acta 1993, 222 (2), 187194.

(22) Guiry, K. P.; Coles, S. J.; Moynihan, H. A.; Lawrence, S. E. Effect of 1-Deoxy-D-Lactose upon the Crystallization of D-Lactose. Cryst. Growth Des. 2008, 8 (11), 3927-3934.

(23) Lerk, C. F.; Andreae, A. C.; de Boer, A. H.; de Hoog, P.; Kussendrager, K.; van Leverink, J. Alterations of $\alpha$-lactose during differential scanning calorimetry. J. Pharm. Sci. 1984, 73 (6), 856-857.

(24) Willart, J. F.; Caron, V.; Lefort, R.; Danède, F.; Prévost, D.; Descamps, M. Athermal character of the solid state amorphization of lactose induced by ball milling. Solid State Commun. 2004, 132 (10), 693-696.

(25) Jawad, R.; Elleman, C.; Vermeer, L.; Drake, A. F.; Woodhead, B.; Martin, G. P.; Royall, P. G. The Measurement of the $\beta / \alpha$ Anomer Composition Within Amorphous Lactose Prepared by Spray and Freeze Drying Using a Simple 1H-NMR Method. Pharm. Res. 2012, 29 (2), 511-524.

(26) Herrington, B. L. Some Physico-Chemical Properties of Lactose. J. Dairy Sci. 1934, 17 (10), 659-670.

(27) Hunziker, O. F.; Nissen, B. H. Lactose Solubility and Lactose Crystal Formation: I. Lactose Solubility. J. Dairy Sci. 1926, 9 (6), 517537.

(28) Hunziker, O. F.; Nissen, B. H. Lactose Solubility and Lactose Crystal Formation: II. Lactose Crystal Formation. J. Dairy Sci. 1927, 10 (2), 139-154.

(29) Zeng, X. M.; Martin, G. P.; Marriott, C.; Pritchard, J. The Influence of Crystallization Conditions on the Morphology of Lactose Intended for Use as a Carrier for Dry Powder Aerosols. J. Pharm. Pharmacol. 2000, 52 (6), 633-643.

(30) Omar, C. S.; Dhenge, R. M.; Osborne, J. D.; Althaus, T. O.; Palzer, S.; Hounslow, M. J.; Salman, A. D. Roller compaction: Effect of morphology and amorphous content of lactose powder on product quality. Int. J. Pharm. 2015, 496 (1), 63-74.

(31) Kaialy, W.; Nokhodchi, A. Antisolvent crystallisation is a potential technique to prepare engineered lactose with promising aerosolisation properties: effect of saturation degree. Int. J. Pharm. 2012, 437 (1), 57-69.

(32) Nickerson, T. A. Lactose Crystallization in Ice Cream. IV. Factors Responsible for Reduced Incidence of Sandiness. J. Dairy Sci. 1962, 45 (3), 354-359.

(33) Nickerson, T. A. Lactose Crystallization in Ice Cream. I. Control of Crystal Size by Seeding. J. Dairy Sci. 1954, 37 (9), 1099-1105.

(34) Griffiths, R. C.; Paramo, G.; Merson, R. L. Preliminary investigation of lactose crystallization using the population balance technique; AIChE Symposium Series; American Institute of Chemical Engineers: 1982.

(35) Larhrib, H.; Martin, G. P.; Prime, D.; Marriott, C. Characterisation and deposition studies of engineered lactose crystals with potential for use as a carrier for aerosolised salbutamol sulfate from dry powder inhalers. Eur. J. Pharm. Sci. 2003, 19 (4), 211-221.

(36) Leviton, A. Methanol Extraction of Lactose and Soluble Proteins from Skim Milk Powder. Ind. Eng. Chem. 1949, 41 (7), 1351-1357.

(37) Brito, A. B. N.; Giulietti, M. Study of lactose crystallization in water-acetone solutions. Cryst. Res. Technol. 2007, 42 (6), 583-588.

(38) Machado, J. J. B.; Coutinho, J. A.; Macedo, E. A. Solid-liquid equilibrium of $\alpha$-lactose in ethanol/water. Fluid Phase Equilib. 2000, 173 (1), 121-134. 
(39) Vu, L. T. T.; Durham, R. J.; Hourigan, J. A.; Sleigh, R. W. Dynamic modelling and simulation of lactose cooling crystallisation: from batch and semi-batch to continuous operations. Comput.-Aided Chem. Eng. 2005, 20, 493-498.

(40) Siddique, H.; Brown, C. J.; Houson, I.; Florence, A. J. Establishment of a Continuous Sonocrystallization Process for Lactose in an Oscillatory Baffled Crystallizer. Org. Process Res. Dev. 2015, 19 (12), 1871-1881.

(41) Shi, Y.; Liang, B.; Hartel, R. W. Crystallization Kinetics of Alpha-Lactose Monohydrate in a Continuous Cooling Crystallizer. J. Food Sci. 1990, 55 (3), 817-820.

(42) Bund, R. K.; Pandit, A. B. Rapid lactose recovery from buffalo whey by use of 'anti-solvent, ethanol'. J. Food Eng. 2007, 82 (3), 333341.

(43) Dong, Y.; Ng, W. K.; Hu, J.; Shen, S.; Tan, R. B. H. A continuous and highly effective static mixing process for antisolvent precipitation of nanoparticles of poorly water-soluble drugs. Int. J. Pharm. 2010, 386 (1-2), 256-261.

(44) Rjabova, A. E.; Kirsanov, V. V.; Strizhko, M. N.; Bredikhin, A. S.; Semipyatnyi, V. K.; Chervetsov, V. V.; Galstyan, A. G. Lactose Crystallization: Current Issues and Promising Engineering Solutions. Food Raw Mater. 2013, 1 (1), 66-73.

(45) Kaialy, W.; Martin, G. P.; Ticehurst, M. D.; Royall, P.; Mohammad, M. A.; Murphy, J.; Nokhodchi, A. Characterisation and Deposition Studies of Recrystallised Lactose from Binary Mixtures of Ethanol/Butanol for Improved Drug Delivery from Dry Powder Inhalers. AAPS J. 2011, 13 (1), 30-43.

(46) Subra, P.; Jestin, P. Screening Design of Experiment (DoE) Applied to Supercritical Antisolvent Process. Ind. Eng. Chem. Res. 2000, 39 (11), 4178-4184.

(47) Lindenberg, C.; Krättli, M.; Cornel, J.; Mazzotti, M.; Brozio, J. Design and Optimization of a Combined Cooling/Antisolvent Crystallization Process. Cryst. Growth Des. 2009, 9 (2), 1124-1136.

(48) Svoboda, V.; MacFhionnghaile, P.; McGinty, J.; Connor, L. E.; Oswald, I. D. H.; Sefcik, J. Continuous Cocrystallization of Benzoic Acid and Isonicotinamide by Mixing-Induced Supersaturation: Exploring Opportunities between Reactive and Antisolvent Crystallization Concepts. Cryst. Growth Des. 2017, 17 (4), 1902-1909.

(49) Beevers, C. A.; Hansen, H. N. The structure of [alpha]-lactose monohydrate. Acta Crystallogr., Sect. B: Struct. Crystallogr. Cryst. Chem. 1971, 27 (7), 1323-1325.

(50) Garnier, S.; Petit, S.; Coquerel, G. Dehydration Mechanism and Crystallisation Behaviour of Lactose. J. Therm. Anal. Calorim. 2002, 68 (2), 489-502.

(51) Platteau, C.; Lefebvre, J.; Affouard, F.; Derollez, P. Ab initio structure determination of the hygroscopic anhydrous form of [alpha]lactose by powder X-ray diffraction. Acta Crystallogr., Sect. B: Struct. Sci. 2004, 60 (4), 453-460.

(52) Platteau, C.; Lefebvre, J.; Affouard, F.; Willart, J.-F.; Derollez, P.; Mallet, F. Structure determination of the stable anhydrous phase of [alpha]-lactose from X-ray powder diffraction. Acta Crystallogr., Sect. B: Struct. Sci. 2005, 61 (2), 185-191.

(53) Lefebvre, J.; Willart, J.-F.; Caron, V.; Lefort, R.; Affouard, F.; Danede, F. Structure determination of the $1 / 1$ alpha/beta mixed lactose by X-ray powder diffraction. Acta Crystallogr., Sect. B: Struct. Sci. 2005, 61 (4), 455-463. 